\title{
PROCEEDINGS AND REPORTS OF UNIVERSITIES COLLEGES, COUNCILS AND ASSOCIATIONS
}

\section{GREAT BRITAIN}

\section{UNIVERSITY OF LONDON}

\section{PROFESSOR OF ORTHOPAEDICS}

Mr Richard Geoffrey Burwell has been appointed to the Chair in Orthopaedics of London University tenable at the Institute of Orthopaedics at the Royal National Orthopaedic Hospital in succession to the first professor, Sir Herbert Seddon, who retired last year.

Professor Burwell had a distinguished undergraduate career at Leeds, where he won the Medical Scholarship, the Waddington and Littlewood Prizes in anatomy, the Infirmary Scholarship, the Hardwicke Prize in medicine and the Edward Ward Prize in surgical anatomy. He gained first class honours in anatomy in the B.Sc.; qualified M.B., Ch.B., with honours, in 1952; gained distinction in the M.D. in 1955, and became F.R.C.S. in the same year. After filling successive posts of house surgeon, demonstrator in anatomy, casualty officer and orthopaedic officer at Leeds, he became house surgeon at the British (now Royal) Postgraduate Medical School before joining the Army for his two years' national service as surgical specialist in military hospitals both in this country and overseas. Thereafter he held the posts of orthopaedic registrar, lecturer in anatomy and lecturer in surgery at Leeds. His time as Lecturer in Anatomy under the late Professor Archibald Durward provided him with a firm groundwork of cellular biology in a department which is in the forefront of modern anatomical science. By working for a further two years in the Surgical Unit at Leeds under Professor J. C. Goligher he was able to widen his experience of general surgery and clinical teaching. Going on from there he became orthopaedic registrar and then senior registrar and senior resident surgical officer at the Robert Jones and Agnes Hunt Orthopaedic Hospital, Oswestry.

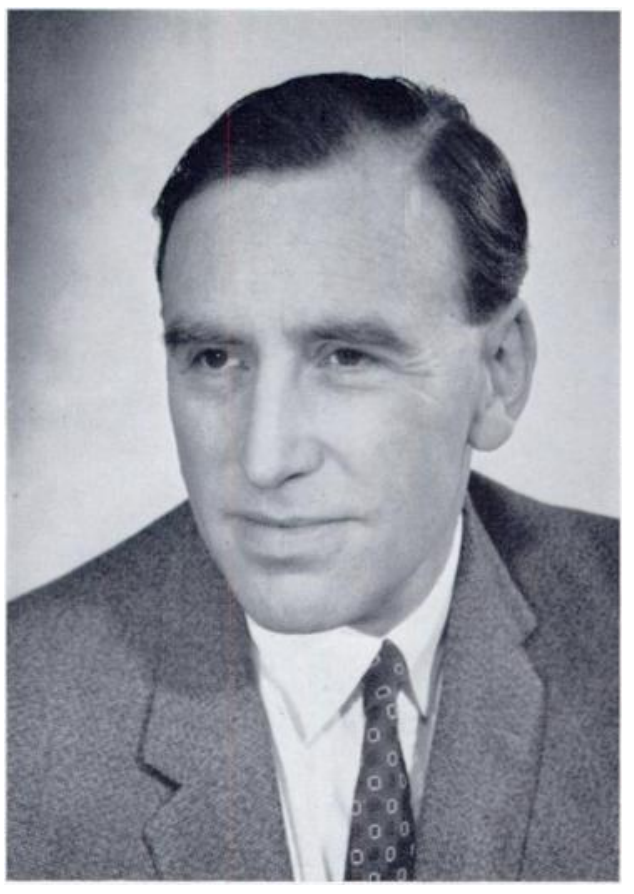

He will take up his full duties on October 1, the beginning of the forthcoming academic year. In the meantime he has a programme of travel in Europe and North America, and is taking the opportunity to plan the future activities of his department.

Professor Burwell is of the younger school but a man of mature judgement. He has a lively and original mind and has published widely. He is particularly interested in fundamental problems, such as tissue transplantation, immunology, growth, repair and the causation of disease, as readers will surmise from his papers in this journal. He has had a very warm welcome at the Institute of Orthopaedics and the Royal National Orthopaedic Hospital. A man of immense energy, he already shows the leadership that transcends command and that characterises our own professorial system at its best.

\section{THE NUFFIELD FOUNDATION}

\section{THIRD NUFFIELD CONFERENCE ON RHEUMATISM}

In April 1967 the Nuffield Foundation held its third two-day conference between rheumatologists and biological scientists from other disciplines on the possible underlying causes of rheumatic disease. The conference had two main themes-the synthesis and breakdown of collagen, and the possibility 
of infection by such organisms as mycoplasmas and Bedsonia. In the very full programme there were papers on the morphology of cartilage, collagen crosslinks, the turnover and breakdown of collagen, cathepsins, the structure of mucopolysaccharides, the localisation of connective-tissue polyanions in cartilage, lubrication of joints, elastin biosynthesis, experimental arthritis, isotopic labelling, mycoplasma arthritis and isolation of the organisms and Bedsonia. The conference proceedings are available without charge to those interested, on application to the Director, The Nuffield Foundation, Nuffield Lodge, Regent's Park, London, N.W.1.

\title{
SCIENTIFIC SOCIETIES AND REGIONAL ORTHOPAEDIC CLUBS
}

\author{
SOUTH WEST ORTHOPAEDIC CLL'B
}

A meeting of the Club was held on November 11, 1967.

A new operation for the valgus foot-Mr Dillwyn Evans (Cardiff) described a method of correcting the severely valgus foot, in which the navicular is subluxated laterally on the neck of the talus. The principle of the operation is lengthening of the calcaneus by a vertical osteotomy just behind the calcaneo-cuboid joint. The osteotomy is kept open with tibial bone grafts and, if properly done, it leads to reduction of the talo-navicular subluxation.

Unsuccessful McMurray osteotomies-Mr $R$. Merryweather (Gloucester) had reviewed a personal series of eighty-eight osteotomies. Six patients had developed progressive collapse of the femoral head after an otherwise satisfactory osteotomy with sound union. In all six patients there had been evidence of some flattening of the femoral head in the six months before operation. These changes may be a warning that osteotomy might fail.

\section{AUSTRALIA}

\section{AUSTRALIAN AND NEW ZEALAND ORTHOPAEDIC ASSOCIATIONS}

A joint meeting of the Australian and New Zealand Orthopaedic Associations was held in Adelaide from October 2 to 6, 1967.

Giant-cell tumour of bone-Mr W. M. Wearne (Melbourne) had studied thirty-nine cases of giant-cell tumour. Characteristically a greater proportion of females were affected than with other tumours in bone. Of twelve patients originally treated by curettage or partial excision, seven ( 58 per cent) had recurrences. In three cases widespread metastases developed, indicating malignant change; initial treatment had been curettage. Despite the so-called classical appearance of this tumour, radiologists were prepared to make a definite diagnosis in less than 30 per cent, so that diagnosis was very dependent on biopsy, as in most other bone tumours. Because many of these tumours are near the knee and often recur after curettage, he favoured block excision, and when the tumour was confined to one tibial or femoral condyle it was better to perform block excision and arthrodese the knee by means of a Küntscher nail or a graft slid from the adjacent healthy tibia or fibula. Giant-cell tumour occasionally occurred at the site of Paget's disease, in which most tumours were highly malignant. $\mathrm{Dr} H$. S. Sandhu (Patiala, India) agreed that recurrence after curettage was frequent. He recommended excision when possible. Dr F. P. Dewar (Toronto, Canada) said that in his department the lesion was considered essentially benign. He would excise the tumour if possible but rather than sacrifice a good knee would curette and pack with bone chips. $M r R$. G. White (Adelaide) cited a case of giant-cell tumour of the upper end of the tibia treated by curettage, deep x-ray, and then bone grafting nine months later. Twenty-seven years later an osteosarcoma appeared, probably caused by the irradiation. Mr Wearne, in reply to $\mathrm{Mr} H$. B. Crock (Melbourne), agreed that recognition of recurrences could be difficult, and that if recurrence occurred block excision was the treatment of choice.

Primary malignant tumours of calcaneal tendon-Mr W.S. Stening (Sydney) reported three cases. One was of malignant synovioma which was treated by wide local block dissection followed by irradiation; the patient died one year after operation. The other two were fibrosarcomata; both were treated by block excision and the patients have survived for eleven years. A wide search of the literature had failed to disclose the presence of fibrosarcoma occurring in tendon. Malignant synovioma was usual in relation to joints but extremely rare in tendon. Therefore, the presence of unexplained lumps in the calcaneal tendon should be treated with great suspicion and biopsy always done. $M r B . T$. Keon-Cohen (Melbourne) had seen six patients with unexplained swellings in the calcaneal tendon, most after injury; he ascribed the swellings to partial rupture with mild subsequent inflammatory 
changes. He had been able to excise the swelling in each case. $\mathrm{Mr} \mathrm{J}$. Jens (Ballarat) had similar experience and $M r R$. Middleton (Sydney) considered that unexplained swellings could be associated also with hyperlipaemia and later coronary occlusion.

Leg lengthening by open osteoclasis-Mr K. R. Daymond (Sydney) described results of a one-stage procedure of leg lengthening by the Anderson technique in sixteen patients, aged from eight to fifteen and a half years; increase in length varied from 3.8 to 5.7 centimetres ( $1 \frac{1}{2}$ to $2 \downarrow$ inches). The creation of a tibio-fibular synostosis and the osteoclasis were both performed at the one stage together with lengthening of the calcaneal tendon if it was tight; the fibula was fixed to the lower end of the tibia by a screw. Advantages of this method over others were that accurate lengthening up to 5 centimetres ( 2 inches) could be obtained, risk of infection was very slight, the scar was invisible and there was very little pain. There were no notable complications. $M r$ G. C. Colvin (Sydney) had practised oblique osteotomy for seventeen years and had gained up to 11.4 centimetres ( $4 \frac{1}{2}$ inches) in length. This procedure was preferable in a child over twelve years old. He used a footpiece incorporated in the splint to prevent equinus. Mr P. Williams (Melbourne) had used both methods and preferred the osteoclasis. He did not lengthen the calcaneal tendon. If equinus was not resisted, degeneration of the articular surface of the ankle could result. Concluding, Mr Daymond said that in a child over the age of fourteen years leg shortening was preferable. He had not encountered any trouble with the articular cartilage of the ankle.

MacIntosh prosthesis in rheumatoid arthritis-Dr F. P. Dewar (Toronto, Canada) outlined the technique of the MacIntosh arthroplasty, which had now been accepted throughout the world. The indication was loss of the articular surface from both femur and tibia, associated with flexion, valgus or varus deformity at the knee. It was designed primarily to relieve pain. One hundred and three operations had now been done in Toronto, with good relief of symptoms in seventy-six cases. The technique was demonstrated in a film. In patients with bilateral affection the second knee was treated six months after the first. He stressed the importance of inserting the prosthesis exactly to the extreme back of the tibia, and that the prosthesis on one side might need to be thicker than on the other, according to the degree of deformity.

Hallux valgus in the adolescent-Mr R. E. Blunden (Christchurch) presented a study of seventy-five cases treated by distal osteotomy of the first metatarsal bone. The various types of corrective procedure were reviewed but he preferred the Mitchell type of osteotomy which had been done on 135 feet. The main disadvantage was the five weeks' immobilisation in plaster. Selection was important, the feet being otherwise normal with no arthritis, metatarsalgia or stiffness of the big toe. The earliest age for the operation was fifteen years. Eighty-five per cent of the feet had excellent results and a further 6 per cent were fair.

Ostentomy of the metatarsal neck for hallux valgus-Mr B. J. Dooley (Melbourne) presented the results of oblique osteotomy of the metatarsal head and neck done on seventeen patients between 1962 and 1966. The technique accorded with Wilson's except that, recently, resection of the medial eminence was not done because he considered that the less the interference with the metatarso-phalangeal joint the better. Follow-up was for not less than one year and not more than five. The hallux was shortened by an average of 1 centimetre and the width of the foot reduced by 1 centimetre. The average intermetatarsal angle was reduced from 15 to 7 degrees. The operation fulfilled two basic orthopaedic principles: the osteotomy was as close as possible to the site of greatest deformity, and a long-standing fixed deformity was best corrected by resection or shortening of bone, thus relaxing the tight ligaments and tendons on the concave side of the deformity -in this instance the lateral capsule and the adductor tendon--to prevent recurrence. In all patients symptoms were relieved; the patients were pleased with the improved appearance and were able to wear all types of shoes. $\mathrm{Mr} F$. H. McC. Callow (Sydney) considered the main cause to be genetic, the influence of shoes being secondary. He agreed that shortening of the metatarsal was essential with the oblique osteotomy. Mr M. B. Menelaus (Melbourne) said that the main problem with adolescent hallux valgus was when to perform a bony and when a soft-tissue operation. Below the age of fifteen years he preferred a soft-tissue procedure such as McBride's and over fifteen years a bony operation. $M r W . A$. Liddell (Christchurch) had found neither shortening nor flexion at the osteotomy site to be essential to a good result. $\mathrm{Mr} \mathrm{J}$. Cloke (Melbourne) stressed the importance of flexing the metatarsal head into the sole and so avoiding the development of a painful second metatarsal head. Mr A. F. Dwyer (Sydney) said that the foot liable to adolescent hallux valgus was one with a loose forefoot often caused by prevailing fashions in footwear. A flat foot was another precipitating factor. He preferred a basal osteotomy because, with a distal operation, a callosity often developed under the second metatarsal head.

Traumatic spondylolisthesis of the axis-Mr B. L. Cornish (Adelaide). This paper was published in the February issue of the Journal of Bone and Joint Surgery (1968).

vol. 50 B, No. 3, AUGUST 1968 
A method of fixing forearm fractures-Mr D. M. Ritchie (Melbourne) reported the results of treating thirty-three forearm fractures with Hicks plates. There were twenty-seven fractures of the radius and ulna, twenty-five of the radius alone and one of the ulna alone. In all, fifty-two bones were plated by six different orthopaedic surgeons. Seven operations were after other procedures. Twenty-six of the thirty-three forearms regained normal function and five were within 50 per cent of normal, and there was no vascular complication, infection or non-union. $M r$ C. Greaves (Sydney) said that although the plate prevented rotation it tended to hold the fragments apart, and in his series he had found some limitation of rotation. $M r R$. Hodgkinson (Sydney) considered that double plating achieved the same purpose, but noted that on removal of the plates the bone was often fragile. Dr F. P. Dewar (Toronto, Canada) said that this was one of the best series that he had seen, but he preferred the use of an intramedullary nail in the ulna and a plate on the radius. MrJ. M. Ellis (Sydney) had used the Hicks plate for the past six years, except for the uppermost third of the radius for which he used an intramedullary nail.

Treatment of femoral subcapital fractures with a sliding nail- $M r W$. A. Parke (Auckland) reviewed cases treated with a sliding nail. Twenty-two of the fractures were of the Garden type 3, and seventeen type 4. He stressed the need for accurate placement of the tri-flanged part of the nail in the centre of the head, and also for the greatest care to avoid penetration of the juxta-articular layer of bone. Advantages claimed for this method were early weight-bearing, shorter stay in hospital and a success rate of 65 per cent; in fourteen cases treatment was considered to have failed. Mr A.F. Dwyer (Sydney) said that 5 per cent of all subcapital fractures were doomed to failure. He could not see any advantage in this technique over a well placed Smith-Petersen nail low in the neck. $\operatorname{Dr} F$. P. Dewar (Toronto, Canada) said that subcapital fractures must continue to be nailed in order to further the study of the causes of avascular necrosis. He preferred the Ken nail. Mr W. Gayton (Melbourne) thought that subcapital fractures should have immediate replacement with a Moore's prosthesis. Mr G. Maguire (Adelaide) agreed that with grossly displaced fractures replacement by a Moore's prosthesis was preferable. $M r$ B. Keon-Cohen (Melbourne) said he always used a Smith-Petersen nail. $M r W$. Swaney (Melbourne) and $M r T$. King (Melbourne) were both strongly opposed to early weight-bearing. $\mathrm{Mr}$ A. Alldred (Dunedin) said that it was wrong to apply one specific line of treatment to a particular fracture, and that each case must be treated on its merits. He stressed that 75 per cent of all patients who suffered a fracture of the neck of the femur were dead within two years. Mr Parke, in reply, said that weight-bearing did not reduce the percentage of good results, and that it was most important to realise that one was treating the patient and not merely a fracture.

Experience with cervical injuries associated with tetraplegia-MrW. A. Liddell (Christchurch) reviewed the activities of the paraplegia unit at the Christchurch Hospital during the first eighteen months. Twenty-four new patients had been admitted, seventeen with cervical injuries. All dislocations were now treated by manual reduction under an anaesthetic as soon as possible. Subsequent management was by light skull traction for a month followed by gradual reduction in the weights over a further two weeks. No brace was used afterwards. In all of eight cases reduction was accomplished without difficulty. One with apparent instability was treated by anterior fusion; the remainder were stable and required no further treatment. Dr F. P. Dewar (Toronto, Canada) said that prolonged traction should be followed by posterior fusion in incomplete lesions. Mr J. E. Critchley (Melbourne) supported Mr Liddell's methods of treatment. Professor A. R. Hodgson (Hong Kong) made a plea for a conservative approach and stressed the necessity of avoiding operation unless one was certain that the fracture-dislocation was unstable. If one had to operate, it was dangerous to use the posterior approach, because an incomplete lesion of the cord might be made complete. $M r G$. M. Bedbrook (Perth) agreed that manual reduction was safe if done gently. In his 200 cases the reduction was stable in 85 per cent. Only 6 to 10 per cent needed operation and this was done late.

Dowel fusion of the ankle joint- $M r M$. R. Hone (Adelaide) described arthrodesis of the ankle by using a dowel which was cut in an antero-posterior plane and then reinserted through 90 degrees. The main advantages compared with other methods were that it was not necessary to take bone from another area, such as the tibia, which was thereby not weakened. $\operatorname{Dr} F$. P. Dewar (Toronto, Canada) found it difficult to see how this ankle fusion would work with the bone plugs loose, and he thought that the Gallie ankle fusion was preferable. This acted best when the graft fitted snugly and therefore was the procedure of choice when the ankle was stiff. Mr Hone in reply to Mr W. E. Spring (Melbourne), who also enquired about the space remaining after the tube of bone had been cut by the dowel, said that the fit of the bone plug did seem to be loose, but it did not matter because ankle fusion occurred.

Harrington rods in scoliosis- $M r W . E$. Doig (Melbourne) reviewed further cases treated by instrumentation in Melbourne since his report at the Australian Orthopaedic Association meeting in Sydney in 1965. Harrington's procedure was followed in all its main principles and the correction 
obtained was holding well. Forty patients had now been treated, with ages ranging from ten to twenty-six years. $M r W . D$. Sturrock (Sydney) had treated thirty-seven patients. He said that curves would progress after the cessation of growth, and cited two patients over the age of forty. He had re-explored two spines and found that by far the most solid part of the fusion had been where the thoracic spine had been treated with a dowel. The vital capacity had improved considerably. $M r O . R$. Nicholson (Auckland) favoured correction in plaster before operation, which was thereby made easier. He always took iliac bone to insert into the dowel holes. He recommended exploration of the fusion routinely to allow any pseudarthrosis to be dealt with.

Acetabular fractures-Mr P. I. Cromack (Perth) made a plea for the conservative treatment of these fractures. Exponents of open reduction and fixation claimed a more accurate reduction, and therefore better functional results, by an approach that was suprapubic, retroperitoneal, Smith-Petersen's or postero-lateral, according to the obliquity of the fracture line. He considered the methods difficult and that the results were not uniformly satisfactory after such big operations. Similarly, results were poor if conventional skin traction only was used. He said that the direction of the traction must be downward and outward; the latter was achieved by the insertion into the neck of the femur of a traction screw-designed in the Royal Perth Hospital-from which a stainless steel traction wire was brought out through a separate stab incision. Traction in the long axis was by a Steinmann pin through the tibia. Lateral traction of 3.5 to 4.5 kilograms ( 8 to 10 pounds) was continued for six to eight weeks; long axis traction of 4.5 kilograms (10 pounds) was kept on for ten to twelve weeks. This was a minor procedure and the functional results were excellent. In his series of twenty-five cases, including all methods of reduction, significant arthritis occurred in 25 per cent, but only one hip was arthrodesed. $\mathrm{Mr}$ H. Barry (Sydney) said that there was little difference in the end-result in cases treated conservatively or by open operation and fixation. $\mathrm{Mr} \mathrm{J}$. Cloke (Melbourne) had reduced the fractures under an image intensifier. When the leg was pulled and abducted, the head of the femur protruded into the pelvis, but when it was adducted, the head of the femur was easily reduced out of the pelvis, and this was important in reduction. Mr F. H. Callow (Sydney) said that fractures with the most displacement gave the best results in function, and he suspected that degenerative changes developed ultimately in all cases. Mr I. McNicol Simith (Melbourne) found at times that, with this method of reduction, while the head of the femur could be moved the acetabular fragment remained displaced.

Ski-ing injuries-Dr W. Beckett Howorth (Greenwich, Connecticut, United States of America) outlined the sources, types and sites of injury caused by ski-ing accidents. The most important cause was loss of control. In two studies that he had made, sprains accounted for about 40 per cent of the injuries, and fractures for 37 per cent. Of the fractures 90 per cent were below the knee and 35 per cent were of the lateral malleolus alone. Dislocations accounted for 5 per cent of injuries, ligament and tendon ruptures for 7 per cent, mainly in the calcaneal tendon. Essential elements in the prevention were training, experience, conditioning, good equipment, courtesy and a proper regard for the rights and safety of others. Mr K. Daymond (Sydney) commented on the high incidence of ankle injuries before the introduction of a high boot. Thereafter, ankle injuries were less common, and fractures in the lower end of the tibia were now the usual finding. $M r$ A. B. MacKenzie (Christchurch) commended the use of inflatable plastic splints as an excellent method of immobilisation of a fracture of the tibia at the site of the accident, and they were of great comfort to the patient. Mr A. R. McKenzie (Dunedin) stressed that there should be extreme care in the application of a plastic splint which must not be applied tightly.

The mechanism of disability and deformity in rheumatoid arthritis-Mr Kingsley $W$. Mills (Melbourne) rejected the concepts of Nichols and Richardson, and of Allison and Ghormley, that all changes in rheumatoid arthritis were secondary to disease of the synovial membrane, which was said to produce a pannus of granulation tissue extending over the articular cartilage and eroding it. From material obtained during synovectomy he had found synovial proliferation and cellular infiltration on a vascular stroma and deposits of ferratin pigment. Bone fragments, the product of joint breakdown, were often found. The proliferating synovial membrane reflected from the cartilage margin invaded the cortex at the site of vascular channels. Once entry was gained, there was progressive spread in the marrow spaces with destruction of bone. The subchondral bone plate was breached and cartilage destruction followed. The cartilage was resistant to destruction, but was affected by marginal undermining and invasion from below. $M r A$. I. Rhydderch (Sydney) confirmed that the chance to save crippling deformities was early synovectomy because this would arrest destruction. $\mathrm{Mr} \mathrm{G}$. Colvin (Sydney) asked whether synovectomy in young children should be done in the early stages of rheumatoid arthritis. $\mathrm{Mr}$ Mills replied that his youngest patient was sixteen and that he would not do a synovectomy at first sight.

VOL. 50 B, No. 3, AUGUSt 1968 
Ischaemic diseases masquerading as orthopaedic lesions-Professor $R$. P. Jepson (Adelaide) outlined the common pitfalls in misdiagnosis, particularly in relation to the popliteal fossa and the adductor opening in the thigh. Often, thrombosis of the popliteal artery might cause pain referred purely to the sole of the foot, and the patient might complain of a sensation like a stone in his shoe; it might even be felt at rest. If thrombosis occurred suddenly, particularly while the patient was walking, there might be severe pain from the calf radiating down to the foot. Such symptoms might be ascribed to root lesions, often because of accompanying numbness-which was explained by the lateral popliteal nerve's obtaining its blood supply from the popliteal artery. The popliteal artery was subject to aneurysm and might produce a swelling behind the knee. Many of the patients also had co-existent osteoarthritis. In the young, a popliteal aneurysm might not be pulsatile. It lay near the posterior periosteum of the femur and periosteal new bone formation would occur; if the patient had a slight fever there was confusion with osteomyelitis. In conclusion he stressed the importance of a thorough clinical examination of the patient and of peripheral pulses. Professor A. R. Hodgson (Hong Kong) said that too often, in a busy practice, the thorough examination of the peripheral pulses was neglected. Mr M. Gallagher (Brisbane) said that the dorsalis pedis was not entirely reliable for peripheral pulsation because of anatomical variations: if it was not present peroneal pulsation should be felt for. $\mathrm{MrO}$. R. Nicholson (Auckland) said that peripheral pulses should be examined after exercise. $\mathrm{Mr} \mathrm{A}$. I. Rhydderch (Sydney) asked if peripheral arterial disease could be present with intact peripheral pulsation. Professor Jepson, in reply, said that this could occur, especially in arterial lesions above the inguinal ligament.

Open reduction of fractures of the radial neck in children-Mr $R$. T. Southwood (Adelaide) reported fourteen cases so treated through a lateral approach, dividing the annular ligament, after closed reduction had failed. At operation there was no difficulty in obtaining good reduction, but instability after reduction was common. In a review, four of the fourteen cases had poor results, which he compared with similar cases in the literature, in which twenty-five out of seventy children had residual disability, usually in the form of restricted rotation. In five cases done recently he had used an approach leaving the annular ligament intact; this seemed to have allowed greater stability of the reduction but it was still too early to assess the final results. $M r W . N$. Gilmour (Perth) agreed with the importance of maintaining the integrity of the annular ligament. The shaft of the radius lay postero-medially and he took the trouble to reduce the shaft rather than the head.

Osteotomy and muscle release for osteoarthritis of the hip-Mr J. C. Beer (Sydney) described the place of accurate correction of the incongruity in the osteoarthritic hip by osteotomy. In an incongruous joint, pressure was transmitted only to those areas of the joint surface which were in contact. Reduction of the load on the joint could be achieved by release of the muscles acting in the frontal plane, the abductors, adductors and iliopsoas. An increase in the weight-transmitting area could be accomplished by adduction osteotomy, which increased the area of effective force transmission, or by abduction osteotomy in properly selected cases, where the large medial osteophyte was made to participate in weight-bearing. It was essential to determine before operation the angle to be made in the neck of the femur, and it was necessary to have accurate radiographs at the time of operation with the hip in abduction and adduction, so that the most congruous position was obtained.

McKee-Farrar and Charnley total hip replacement arthroplasty-Mr J. B. Morris (Auckland) discussed the early results of fifty-eight operations in forty-two patients. The Charnley arthroplasty had been used thirty-nine times and the McKee-Farrar nineteen. Sixteen patients had had both hips replaced, often with different types of prosthesis. The operations had been confined to the very elderly or to younger patients severely crippled by polyarthritis, in whom pseudarthrosis was the only reasonable alternative. The lateral approach to the hip detaching the greater trochanter was preferred to the anterior approach because of the better exposure of the joint and easier fitting of the new hip. Patients stood and walked within the first week, and were ready for discharge after three weeks when one hip had been replaced and after six weeks in bilateral cases. Complications included two superficial wound infections, one dislocation and eleven cases of thrombo-embolism with one fatal and two non-fatal pulmonary emboli. The McKee-Farrar hip gave more pain to the patient initially and the components seized with active movement, but after a few months little difference between the two forms was detectable to the surgeon or the patient.

Rigid internal fixation in osteotomy of the hip using the Osborne-Ball plate-Mr $O$. R. Nicholson (Auckland) reported forty-six osteotomies in which he had used the Osborne-Ball plate; forty-two were for osteoarthritis, one was for protrusio acetabuli and three were for femoral neck fractures. After operation the patient was allowed out of bed on the third day, using crutches, and taking as much weight as was comfortable. The average stay was two to three weeks. There was one failure for technical reasons and one probable non-union. $M r W$. A. Liddell (Christchurch) described a simple 
method of converting the Wainwright spline to make it a compression device. He thought that compression was especially useful in the varus osteotomy. He preferred the antero-lateral approach for hip replacement and did not detach the greater trochanter. In fifty cases of the McKee-Farrar type there had been no mortality and no pulmonary embolism. $M r T$. King (Melbourne) predicted that the total replacement would give trouble in time. He was appalled that old operations for osteoarthritis that had proved reliable should be abandoned for new procedures. He could never understand the mechanics of the spline. The Osborne-Ball appliance had the same basis as the Blount nail, and, while the apparatus itself could not break because it was so heavy, the femur could fracture quite easily in the early stages because only the screws were holding the plate, and these, to him, did not appear strong enough. $M r W$. Pike (Auckland) said that the Osborne-Ball nail would not give a precise angle of varus or valgus if required. There must be careful pre-operative assessment. He was careful to secure, under the image intensifier on the operation table, the greatest degree of congruity. Mr W. Parke (Auckland) agreed with Mr King and thought that we should proceed cautiously with these new procedures. The operation should be used only for the elderly and as a salvage procedure. Dr F. P. Dewar (Toronto, Canada) agreed with Mr J. C. Beer (Sydney) that the main problem was a bio-mechanical one. He always divided the psoas when doing an osteotomy. Mr Kingsley Mills (Melbourne) stressed the need for continuing investigation into the underlying causes of osteoarthritis. $\mathrm{Mr}$ Nicholson, in reply to Mr King, said that the screws in the Osborne-Ball appliance were stronger than standard ones and had been shown to take weight without any harmful effects.

The conservative management of Perthes' disease-Mr J. G. Sweeney (Adelaide) reviewed the results of conservative treatment at the Adelaide Children's Hospital over the last twelve years. One hundred and two patients were available for follow-up. They had been treated by immobilisation either on a frame or in a hip spica, and it was thought that the best results were achieved in the series treated by immobilisation in a hip spica. This also had the advantage of permitting nursing care at home, and a shorter immobilisation. Further, the immobilisation was more complete because children could alter the traction on a frame, and interrupt the immobilisation. Radiographic changes appeared to progress more quickly in patients treated in plaster and the results were less poor. He paid tribute to the late Lansell Bonnin who had introduced this method of treatment to the Adelaide Children's Hospital. Mr P. F. Williams (Melbourne) said that over the past twenty years at the Royal Children's Hospital, Melbourne, practically every method of treatment had been tried. In the past eight years treatment in patten ended calipers had not produced any significant improvement in results. He thought that the best treatment was in a plaster spica, but the lower limbs should be immobilised in abduction, flexion and medial rotation to restore the best congruity. Immobilisation might last up to two years.

The management of orthopaedic disabilities in spina bifida-Mr M. B. Menelaus (Melbourne) said there were four mechanisms of deformity. The first was muscle imbalance due to flaccidity. If the psoas was acting and the gluteus maximus was flaccid, a flexion deformity would develop, which was the basis of the tendon transplant of Sharrard. If the adductors were overacting, transfer of the adductor origin to the ischial tuberosity gave added extension to the hip. The second mechanism was spasticity. This frequently affected the hamstrings or the calf and was best treated by the Eggers's transplant. The third factor was the stiff arthrogrypotic type of foot. Soft-tissue correction was not reliable and excision of the talus had given good results. The fourth feature was the habitually assumed posture of flexion and lateral rotation. This was caused by over-activity of the obturator externus, which held the hip in lateral rotation deformity. This was best treated by dividing the external rotators posteriorly and reefing the lax anterior capsule. Mr A. McSweeney (Brisbane) asked about the treatment of the calcaneus foot. $M r H . V$. Crock (Melbourne) asked if there was any method of preventing the deformity due to habitual posture. Mr J. Gallagher (Brisbane) asked the best age for the psoas transplant. $M r A$. B. MacKenzie (Christchurch) said that a fracture in spina bifida could unite with excess callus. Mr Menelaus, in reply, said that the calcaneus foot was best treated by insertion of the tibialis anterior, extensor digitorum and peroneus brevis into the heel with tenodesis of the calcaneal tendon. The parents should be encouraged to keep the hips in the adducted position, to prevent the deformity due to habitual posture. The best age for the psoas transplant was about eighteen months. Often a varus-rotation osteotomy had to be done and the bone should be big enough to hold a plate. A child with a fracture should be handled extremely carefully, because excess callus often formed after release from a plaster spica.

Mechanism of dislocation in congenital dislocation of the hip-Mr W. H. Huffam (Geelong, Victoria) in a clinical and experimental study had shown that the initial dislocation was backwards, but that the head then rotated round the acetabulum from a posterior to a superior position as the legs extended, swinging on the elongated capsule of the hip. During this phase the dislocation appeared to be greatest in an antero-posterior radiograph and the femoral heads appeared to be further out of the acetabulum but they had, in fact, only moved from the posterior to the superior position with the head of the

vol. 50 B, NO. 3, AUGUST 1968 
femur lying against the side of the pelvis. Rotation of the femur developed to allow the head and neck of the femur to lie beside the pelvis while the foot pointed straight ahead. As this rotation occurred, a fold of capsule and glenoid labrum was compressed inwards to form the limbus. There was then adaptive shortening of the adductor and psoas muscles. Dr M. Beckett Howorth (Greenwich, Connecticut, United States of America) said that studies of congenital dislocation of the hip should eliminate certain fallacies such as there being no primary dysplasia of the acetabulum which was secondary to pressure of the head, that there was no hour-glass contracture of the capsule and that there was no inversion of the limbus.

Spondylolisthesis in childhood-Mr $P$. Kudelka (Melbourne) had reviewed thirteen patients, seven of whom had had spinal fusion after conservative treatment had failed to relieve severe symptoms. All were girls aged ten years or more at operation, all complained of some limitation of sporting ability and of aching and tiredness in the back and legs; they showed limited spinal movements, but straight leg raising was free and reflexes present. All were considered to have radiological fusion. There was evidence suggesting that the neural arch had developed abnormally, either with poorly formed facets in the lumbo-sacral segment or with an abnormally weak pars interarticularis which had separated with slight trauma. There was little evidence that displacement inevitably progressed, and it appeared quite safe to wait, observe and assess the lesion with serial radiography. $\operatorname{Dr} F$. P. Dewar (Toronto, Canada) did not understand the method of slip of one vertebra on another in a child, because he thought that in adult life the slip was caused by disc degeneration. He now favoured fusion between the transverse processes and the ala of the sacrum through bilateral incisions. $M r A$. I. Rhydderch (Sydney) thought that in childhood the pain was much more severe and the spasm greater than in the adult, not only in the back but particularly in the hamstrings. He preferred anterior fusion. Mr B. L. Cornish (Adelaide) said that the reason for pain after operation, particularly in the calf, was a continued traction effect on the cauda equina because of the S-shaped bend at the lumbo-sacral junction. $\mathrm{Mr}$ A. Alldred (Dunedin, New Zealand) considered that there was a strong hereditary basis for spondylolisthesis, with which Mr Kudelka agreed.

Lumbar discography: indications and complications-Mr H. V. Crock (Melbourne) had done 112 lumbar discographs and he said that the investigation should be done by the surgeon managing the case. The needle should be inserted in three spaces: between the third and fourth lumbar, fourth and fifth lumbar and fifth lumbar and first sacral vertebrae because several discs might be in trouble. Forty per cent of patients with disc affections showed no evidence of disc degeneration in a plain radiograph. It was essential always to look for extrusion of the opaque fluid into the body, which might reproduce the patient's symptoms. When a discograph was normal, care must be taken to examine the plain radiograph to exclude other lesions, particularly anomalies of facets. He felt that discography was a very useful investigation for patients with intractable back pain who had failed to respond to conservative treatment, and particularly cases of failed laminectomy and lumbar spondylosis. $\mathrm{Mr} C$. Hudson (Sydney) said he was doing this investigation much less often. It could be difficult and timeconsuming, and was not devoid of complications. It was rather to confirm a diagnosis than make one. Mr A. I. Rhydderch (Sydney) said that one of the main causes of failure of spinal fusion was multiple disc degeneration and this was a real indication for discography. He would prefer to make the level of the rupture on clinical and neurological signs and would only use discography when ready to follow with operation.

Presidential address-Mr $R$. L. Stephen (Sydney) gave a most illuminating, historical and amusing account of the surgical procedures of the past. Orthopaedics as a speciality today was a modern art, but all should be aware of those who had pioneered the art. He recalled the treatise on fractures and dislocations by Hippocrates who distinguished open fractures from closed, and the art of the anatomist Galen. Susrata in about A.D. 500 in India was using an iron prosthesis for his amputees. After tracing numerous developments of surgery throughout history, he concluded that the objects of all famous men were the same as the objects of our own Orthopaedic Association, mainly to increase our knowledge so that we might help those who needed it, to pass on our knowledge to others, and to stimulate others in the search for further knowledge. He stressed the importance of regular meetings such as the present one, and the necessity of further international meetings and the great advance that could be shared in knowledge by peoples of all countries. He thanked the orthopaedic surgeons of other nations who were present at the meeting in Adelaide.

\section{AUSTRALIAN ORTHOPAEDIC ASSOCIATION}

In January, the Association has, for the first time, added to its regular circulars a formal printed annual report. This is for 1967. It is prefaced by a brief account of the founding in 1936, with mention of the leading part that Mr A. R. Hamilton played in its birth and development. The President, 
Mr J. Jens, sends a message recalling the approach of the Combined Meeting in 1970 to be held in Sydney, birthplace of the Association. Mention is made of the future inclusion of an Australian among the British travelling fellows on all future tours instead of alternate ones, and of an annual fellowship for an Australian orthopaedic surgeon in Professor J. I. P. James's department in Edinburgh. Subcommittees on orthopaedic training, on implants, on insignia, and particularly on organisation of the 1970 meeting, have been extremely active. We welcome this first report, which is very well done, and we look forward to its successors.

\section{INDIA}

\section{INDIAN ORTHOPAEDIC ASSOCIATION}

A meeting of the Association was held at Bikaner from August 12 to 14, 1967. The Chairman was Dr M. Natarajan. The meeting started with an instructional course in which Professor R. Garst and $\operatorname{Dr}$ L. H. Lobo (Ludhiana) outlined the causes of chronic low backache and they also dealt with the lumbar intervertebral disc syndrome. $\operatorname{Dr} M$. G. Deo (New Delhi) gave the present ideas on the dynamics of bone growth, and made special reference to alterations that occurred because of malnutrition. After this there was a symposium on the residual paralyses of the foot in which $\operatorname{Dr} K$. T. Dholakia (Bombay), Professor M. N. Kathju (Ajmer) and $\operatorname{Dr}$ S. K. Balchandani (Bombay) described the various operations that might be done on feet that had become deformed after poliomyelitis. Other papers were then read which are listed below.

A preliminary report on scoliosis and Harrington rod instrumentation-Dr R. N. Mitra (Calcutta); Traumatic anterior dislocation of the hip-Professor N. D. Aggarwal (Patiala); Sub-acute osteomyelitisDr D. A. Patel (Ahmadabad); Rheumatoid arthritis in West Bengal-Dr K. S. Bose (Calcutta); Iliac osteotomy in the management of ectopic bladder-Professor M. Natarajan (Madras); Iliac osteotomy for ectopic bladder with the use of a special splint-Professor $B$. N. Sinha and $\operatorname{Dr} A$. N. Srivastava (Lucknow); Amino-aciduria in osteomalacia and rickets-Professor A. K. Gupta and $\operatorname{Dr} P$. K. Sen (Kanpur); Rehabilitation of paraplegics-Dr S. B. Kohli (New Delhi); Osteotomy-osteoclasis of the upper tibia-Dr J.S. Makhani (Bareilly); Bone and joint tuberculosis- $\operatorname{Dr}$ M. T. Mehta (Ahmadabad); Modification of footwear for the anaesthetic feet of lepers-Professor $\mathrm{P}$. K. Sethi and $\mathrm{Dr}$ S. C. Kasliwal (Jaipur); An experimental study of avascular necrosis of the femoral head-Dr V. Mahadevan (Mangalore); Glomus tumour of the knee- $D r C$. K. Sarma (Tirupati).

A clinical demonstration was arranged by Professor M. N. Kathju (Ajmer).

\section{ANNOUNCEMENTS}

\section{BRITISH ORTHOPAEDIC ASSOCIATION SPRING MEETING 1969}

The spring meeting of the British Orthopaedic Association will be held in Glasgow from April 10 to 12, 1969. Those wishing to submit papers for presentation should send six copies of a short abstract (about 400 words) to the Honorary Secretary, British Orthopaedic Association, at the Royal College of Surgeons, Lincoln's Inn Fields, London, W.C.2, not later than December 31, 1968.

\section{BRITISH ORTHOPAEDIC ASSOCIATION TRAVELLING SCHOLARSHIPS}

The British Orthopaedic Association is offering two United Kingdom Travelling Scholarships for 1969 of $£ 200$ each. Applications (twenty copies), which should include a proposed itinerary and the name of one referee, should be sent to the Honorary Secretary, British Orthopaedic Association, at the Royal College of Surgeons, Lincoln's Inn Fields, London, W.C.2, to arrive not later than December 31, 1968.

The award of this Scholarship will be in no way prejudicial to an application for another Scholarship or Fellowship of the Association.

\section{COMBINED MEETING OF ENGLISH-SPEAKING ORTHOPAEDIC ASSOCIATIONS} Sydney, Australia, April 11-17, 1970

The Fifth Combined Meeting will be held at the Wentworth Hotel, Sydney, Australia. Approximately nine papers, each of fifteen minutes' duration, have been allotted to the British 
Orthopaedic Association. Those wishing to submit papers for presentation should send six copies of a short abstract (about 400 words) to the Honorary Secretary, British Orthopaedic Association, at the Royal College of Surgeons, Lincoln`s Inn Fields, London, W.C.2, not later than December 31, 1968.

\section{BRITISH CLUB FOR SURGERY OF THE HAND}

The British Club for Surgery of the Hand will hold an Instructional Course in Hand Surgery at the London Hospital on November 15, 1968, from 9.30 a.m. to 5 p.m. The programme will consist of lectures, films and demonstrations on the treatment of tendon injuries. Further particulars may be obtained from the honorary secretary, Mr H. Graham Stack, Westhay, Mount Avenue, Hutton, Essex.

\section{AMERICAN ACADEMY OF ORTHOPAEDIC SURGEONS}

The In-Training Examination sponsored by the American Academy of Orthopaedic Surgeons will be given on November 16, 1968. Examinations will be available to all orthopaedic residents in the United States and abroad through their training programmes. Announcements to chiefs of all training programmes will be sent on October 7. The fee for American residents will be \$10. Residents outside the United States who desire to take the examination may do so. Applications must be received through their training programmes by October 7, 1968. Announcements will be mailed to members of the American Academy of Orthopaedic Surgeons who desire to take the examination on October 7. The fee for members of the Academy will be \$25. All men who have finished their residency training but who are not yet members of the Academy may take the examination. Applications must be made to the Central Office of the American Academy of Orthopaedic Surgeons by October 7. The fee for this group will be \$25. Individuals outside the United States who wish to take the examination may do so. Letters of application from these individuals must be received at the Central Office of the Academy by October 7.

\section{AUSTRIAN SOCIETY FOR ACCIDENT SURGERY}

The Fourth Congress of the Austrian Society for Accident Surgery will be held on October 11 and 12,1968, in Salzburg. The subject will be amputation and limb fitting. Further information may be obtained from the Secretary, Webergasse 2, Vienna, Austria. 